\title{
Slope stability analysis using anisotropic and nonlinear failure criteria
}

\author{
J.F. Wang \\ Institute of Mechanics, Chinese Academy of Sciences, Beijing, PR China
}

\author{
Z.Y. Chen \\ China Institute of Water Resources and Hydropower Research, Beijing, PR China
}

K.T. Chang

Department of Civil Engineering, Kumoh National Institute of Technology, Gyeongbuk, S/Korea

\begin{abstract}
The shear strength of soils or rocks developed in a landslide usually exhibits anisotropic and nonlinear behavior. The process of sedimentation and subsequent consolidation can cause anisotropy of sedimentary soils or rocks, for instance. Nonlinearity of failure envelope could be attributed to "interlocking" or "dilatancy" of the material, which is generally dependent upon the stress level. An analytical method considering both anisotropy and nonlinearity of the failure envelops of soil and rocks is presented in the paper. The nonlinear failure envelopes can be determined from routine triaxial tests. A spreadsheet program, which uses the Janbu's Generalized Procedure of Slice and incorporates anisotropic, illustrates the implementation of the approach and nonlinear failure envelops. In the analysis, an equivalent Mohr-Coulomb linear failure criterion is obtained by drawing a tangent to the nonlinear envelope of an anisotropic soil at an appropriate stress level. An illustrative example is presented to show the feasibility and numerical efficiency of the method.
\end{abstract}

\section{INTRODUCTION}

Conventional slope stability analyses are normally based on a linear Mohr-Coulomb failure criterion and the assumption that the material is isotropic. Due to the dilatancy effect, the strength envelope of most geotechnical material shows nonlinearity (Charles 1980, Barton \& Choubey 1977, Bandis 1980). Dilatancy effect is also dependent on stress level for a particular problem.

Research has shown that soil mass can marked anisotropic behavior due to, for instance, the process of sedimentation and subsequent consolidation for sedimentary (Bishop 1966, Saada \& Bianchini 1975, Duncan \& Seed 1966). Rock mass also shows anisotropic shear strength along different directions due to the existence of joints (Bandis 1980). The shear strength mobilized may vary with the orientation of failure surface either as a result of material anisotropy or rotation of principal stresses.

A rational method of slope stability analysis should be able to handle nonlinear failure envelopes and anisotropy of material properties caused by, for instance, the slip surface intersecting structural discontinuities in different directions. Research on this has been carried out, but limited to circular slip surfaces
(Lo 1965, Chen et al. 1975, Al-Karni \& Al-Shamrani 2000, Lo \& Lee 1974, Maksimovic 1979, Charles \& Soares 1984). Development of a generalized method which incorporates anisotropic and nonlinear failure criteria is still on-going, partly due to the difficulties involved in the implementing multi-level iterations needed in the computer-programming.

Nowadays, powerful spreadsheets, such as Microsoft Excel, have become a common tool for geotechnical engineers and researchers to assist in their numerical calculations and programming. Multi-level iterations can be performed effectively in spreadsheets, thus facilitating the incorporation of anisotropic a nonlinear failure criteria in slope stability analysis. The flexibility and ease of use, combined with good graphing capabilities, have made spreadsheets the authors' choice in using the tools for performing the slope stability analysis in this paper.

\section{ANISOTROPY AND NONLINEARITY}

\subsection{Anisotropy}

Laboratory testing shows that the angle of internal friction $\phi$ of soils or rocks has limited anisotropic 
behaviour and is largely independent on the directions of external loads. However, the cohesion component $c$ depends to a great extent on the stress path and the test types (Al-Karni \& Al-Shamrani 2000). For simplicity, only dependency of cohesion component $c$ on stress path is considered.

Casagrande \& Carillo (1944) suggested an empirical relationship between cohesion $c$ and the direction of external load or of a bedding surface of soil stratum. Bishop (1966) reformulated this relationship, but keeping the basic form unchanged. If we assume that the plane of anisotropy to be the horizontal in the slope stability, the following relationship can be obtained for the cohesion of a slice.

$c_{1}=c_{h}+\left(c_{y}-c_{h}\right) \cos ^{2} \beta$

where, $c_{v}, c_{h}$ are cohesions along the vertical and horizontal directions respectively; $\beta$ is inclination between the plane of anisotropy and the principal stress $\sigma_{1}$, which is assumed to be the inclination of the resultant interslice forces as shown in Figure 1. Equation 1 can also be expressed as:

$c_{i}=c_{h}+\left(c_{v}-c_{h}\right) \sin ^{2} \beta$

Defining anisotropic ratio as $K=c_{h} / c_{v}$, we have

$c_{i}=c_{\nu}\left[K+(1-K) \sin ^{2} \beta\right]$

Because of the varying directions of resultant interslice force along the slip surface, the cohesion component $c$ must be a function of $\beta$. Therefore, its value needs to be updated by a nested iteration in combination with other variables in the analysis until convergence is attained.

\subsection{Nonlinearity}

The friction angle of soil or rock joints is dependent on the normal stresses. This is attributed to the dependence of dilatancy behaviour on stress level. The geometric configuration and physical properties of shear band is changeable during the whole shearing process. This is often called state or subprocess changeability. The resistance of real shear band will be lessened step by step due to deterioration to some extent through particle contact and extrusion, and also various kinds of softening effects such as fining and rolling of particles within shear band during the process of shearing slip. Generally speaking, if carefully observation was taken under Scanning Electron Microscope using sheared micro samples, one can find that the geometric shape of final real shear band developed in soil mass will be as anomalistic as jagged discontinuity. Therefore, the nonlinearity in soil mass

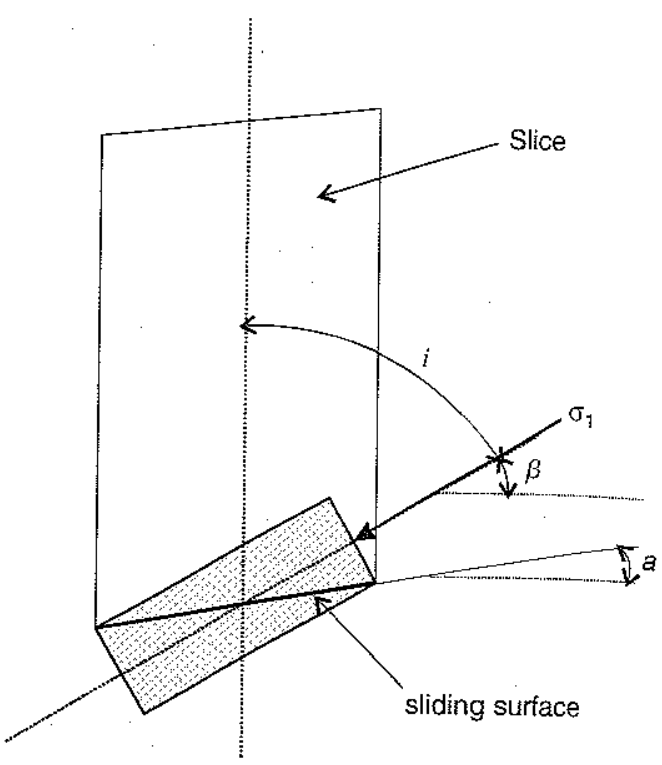

Figure 1. Definition of geometric parameters of the degree of anisotropy of soil cohesion.

induced by "interlocking" or "dilatancy" is ubiquitous. In order to describe the nonlinearity, various failure criterions of nonlineraity have been developed, such as power function, parabola or hyperbola relationship (Zhang \& Chen 1987, Maksimovic 1989, 1992, 1996).

In general, there are great differences in physical condition, configuration and applied load among various slipping surfaces. Therefore, careful checking of nonlinearity of failure envelop of slope forming materials must be carefully carried out in soil mechanics laboratory when analysis a landslide. The range of applied loads in laboratory testing should correspond to the load levels likely to be experienced by the landslide. Of particular importance is the measurement of shear strength at very low normal stresses. These are not difficult tasks that can be accomplished using normal laboratory apparatus.

The nonlinear failure criterion suggested by Maksimovic (1996) is useful, among other available failure criteria. It assumes that the angle of internal friction follows a parabolic relationship with the effective normal stress within the shear band. As shown in Figure 2, the frictional angle is expressed as:

$\dot{\varphi}=\dot{\varphi}_{B}^{\prime}+\frac{\Delta \varphi^{\prime}}{1+\sigma_{n}^{\prime} / p_{N}}$

where, $\varphi^{\prime}=\tan ^{-1}\left(\tau_{f} / \sigma_{n}^{\prime}\right)$

$\phi_{\mathrm{B}}^{\prime}$ is the basic frictional angle, or called the residual frictional angle; $\Delta \phi^{\prime}$ is the maximum difference 

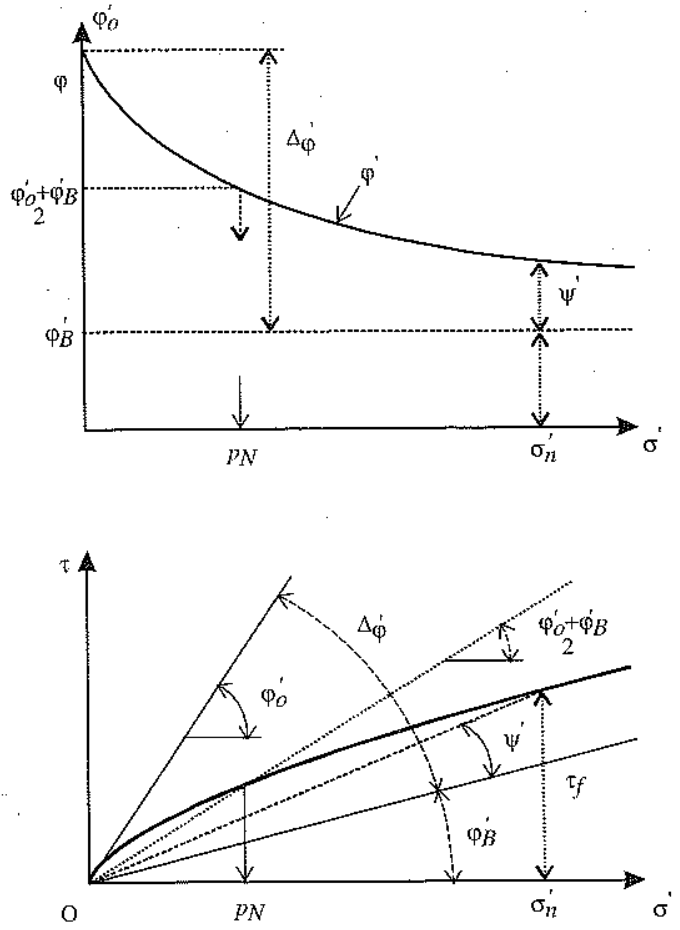

Figure 2. Variation of secant angle of shearing resistance $\phi^{\prime}$ assuming holding an hyperbolic type.

between the peak and residual frictional angles; $p_{\mathrm{N}}$ is the effective normal stress corresponding to $\left(\varphi_{0}^{\prime}+\right.$ $\left.\varphi_{B}^{\prime}\right) / 2$, which can be regarded as the effective normal stress corresponding to $1 / 2$ of the generalized angle of dilation; $\varphi_{0}^{\prime}$ is the effective peak frictional angle.

The criterion can be used to describe the evolutionary process of a variable angle of internal friction varying from a peak value down to lowest value corresponding to the residual shear strength. From Equation 4 , it can be observed that the angle of internal friction consists of two components. The first component represents the basic frictional angle $\phi_{\mathrm{B}}^{\prime}$ under condition of constant volume. The second component which is related to $\Delta \phi^{\prime}$ has the physical meaning of relating the nonlinearity of shear strength to the dilation effect of a granular soil.

The relevant parameters within Equation 4 can be obtained from the data of direct shear or triaxial tests by optimization technique. Zambrano et al. (2003) have suggested such a method of "error-in-variables" for rock failure envelope:

The dependency of the angle of internal friction on normal stresses also necessates a multi-level iteration process in slope stability calculations.

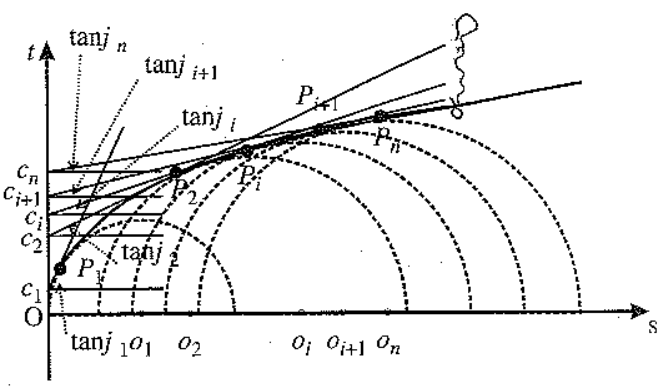

Figure 3. Schematic map of equivalently transferring of nonlinear shearing resistance to Mohr-Coulomb linear relation.

\subsection{Failure criterion considering anisotropy and nonlinearity}

Based on the above considerations, a new improved Mohr-Coulomb criterion is expressed as:

$$
\begin{aligned}
& \tau_{f}=c^{\prime}+\sigma_{n}^{\prime} \tan \varphi^{\prime}=c_{v}^{\prime}\left[K+(1-K) \sin ^{2} \beta\right] \\
& +\sigma_{n}^{\prime} \tan \left(\varphi_{B}^{\prime}+\frac{\Delta \varphi^{\prime}}{1+\sigma_{n}^{\prime} / p_{N}}\right)
\end{aligned}
$$

In this above equation, each parameter has its definite physical meaning.

\section{SLOPE STABILITY ANALYSIS USING ANISOTROPY AND NONLINEARITY CRITERIONS}

A slope stability analysis program using anisotropy and nonlinear criterions based on Janbu's Generalized Procedure of Slice is developed and described herein (Fig. 3). The authors.believe that the results such obtained will be more representative to other approaches that involve more assumptions on the shape of failure surfaces and internal forces. When analyzing a large landsiide, especially when such landslide is complex in the way of constituted material, the presented analysis is preferable to classical methods.

The computing program includes the following steps:

1) Calculate the inclination of resultant interslice force $\beta\left(\beta_{i}=\tan ^{-1}\left(T_{i} / E_{i}\right)\right.$, where $T$ and $E$ are the vertical and horizontal interslice forces respectively) of each slice using the shear strength parameters of a linearized Molnr-Coulomb criterion and the effective normal stress $\sigma_{n}$ calculated using Janbu's Generalized Procedure of Slice based on an initial estimate of $F_{s}$; 
2) Substitute $\beta, \sigma_{n}^{\prime}$ into Equation 3 and 4 and calculate $\tan \phi_{i}^{\prime}$ and $c_{i}^{\prime}$ corresponding to the nonlinear MohrCoulomb failure criterion for each slice;

3) Substitute $\tan \phi_{i}^{\prime}$ and $c_{i}^{\prime}$ into Janbu's equilibrium equations (the equations themselves need a second level iterative operation) in order to get the first estimated value of factor of safety $F_{s}$;

4) Calculate the new $\beta$ and $\sigma_{n}^{\prime}$ using the obtained $F_{s}$ (through $t$ value that is included in $\sigma_{n}^{\prime}$ ) for each slice;

5) Repeat step 2) and calculate the new values of $\tan \phi_{i}^{\prime}$ and $c_{i}^{\prime}$ using the new estimates of $\beta, \sigma_{n}^{\prime}$;

6) Calculate the another new estimate of safety $F_{s}$ using the new $\tan \phi_{i}^{\prime}$ and $c_{i}^{\prime}$ obtained from step 5);

7) If the difference between successive estimates of $F_{s}$ is larger than 0.000001 , then return to step 4), using the latest estimate of $F_{s}$ as input. Repeat the calculations until the convergence criterion $(0.000001)$ is satisfied.

The above iterative procedures can be implemented easily using a spreadsheet.

\section{EXAMPLE PROBLEM}

The example concerns a re-activated landslide initiated at the front part of an old landslide deposit at the Zhaiba landslide area in the newly developed Yunyang county affected by the Three Gorges Project, P.R.China (Fig. 4). The old avalanche/landslide deposit is composed predominately of loose clay embedded with detritus, block rock and erratic boulder. Due to the process of sorting during deposition, the front of the old landslide debris contained many large boulders. The altitudes of the landslide range from $290 \mathrm{~m}$ to $355 \mathrm{~m}$. On average, the re-activated landslide has a length of $270 \mathrm{~m}$, a width of $85 \mathrm{~m}$, an area of $2.0 \times 10^{4} \mathrm{~m}^{2}$ and a volume of $28 \times 10^{4}$ to $30 \times 10^{4} \mathrm{~m}^{3}$ The shape of the new landslide is like a peanut on plan.

Four large-scale direct Yangtze River Scientific Research Institute at the front part of the new landslide has carried out shear box tests. The testing data and fitted results are shown in Figure 5. The fitted results for the linearized Mohr-Coulomb failure envelope are $c=22.13 \mathrm{kPa}$ and $\phi=15.22^{\circ}$. Using optimization technique, the fitted results for Maksimovic's nonlinear Mohr-Coulomb failure are $\phi_{\mathrm{B}}=7.81^{\circ}, \Delta \phi=30.97^{\circ}, p_{\mathrm{N}}=169.48 \mathrm{kPa}$, and the mean square errors of the residuals of curve fitting is 23.3864. It should be noted that the fitting of the hyperbola expression assumes a zero cohesion intercept. The bulk unit weights measured by in-situ tests are $21.4 \mathrm{kN} / \mathrm{m}^{2}$ and $22.5 \mathrm{kN} / \mathrm{m}^{2}$ for natural and saturated state respectively.

The national design code that the minimum factor of safety under the worst combinations of external loads is 1.05 . The results showed that the stability of the original landslide could not meet this minimum.

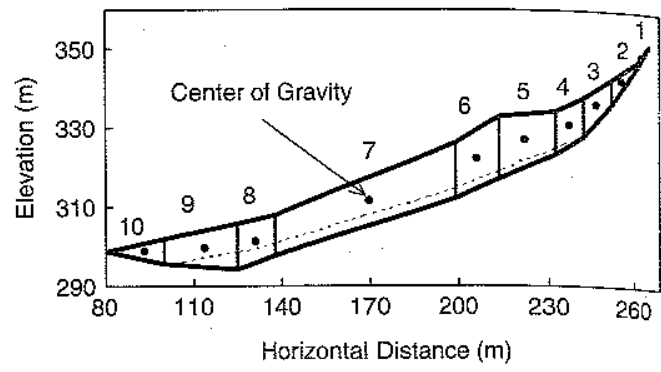

Figure 4. Example problem: Bo Yang Wan landslide in Yunyang county, the Three Gorges, PR China.

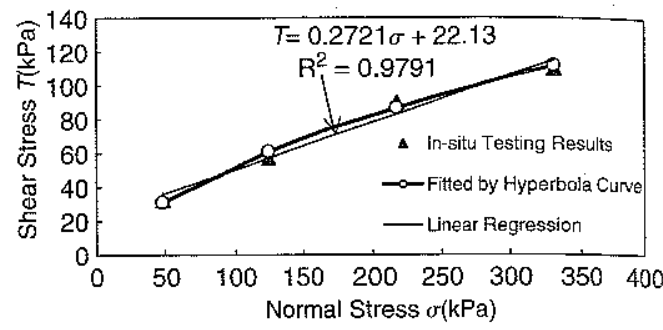

Figure 5. The large scale in site shear test results on the slip surface of Bo Yang Wan landsiide.

Table 1. Results of considering anisotropy and nonlinear of shear strength using Janbu's GPS method*.

\begin{tabular}{|c|c|c|c|c|}
\hline \multirow[b]{2}{*}{$\begin{array}{l}\text { Loading } \\
\text { conditions*** }\end{array}$} & \multirow[b]{2}{*}{$\begin{array}{l}\text { Linear } \\
\text { criterion }\end{array}$} & \multicolumn{3}{|c|}{ Factor of Safety $F_{s}$} \\
\hline & & $\begin{array}{l}\text { Nonlinear } \\
\text { criterion }\end{array}$ & $\begin{array}{l}\text { Anisotropy } \\
\text { criterion }\end{array}$ & $\begin{array}{l}\text { Nonlinear \& } \\
\text { anisotropy } \\
\text { criterion }\end{array}$ \\
\hline (1) (2) & 1.2617 & 1.3347 & 1.0229 & 1.4365 \\
\hline (1) (2) (3) & 1.2493 & 1.3156 & 1.0199 & 1.4132 \\
\hline (1) (2) (3) (4) & 1.2291 & 1.2878 & 1.0194 & 1.3772 \\
\hline (1) (2) (3) (4) (5) & 1.0259 & 1.0766 & 0.8475 & 1.1494 \\
\hline
\end{tabular}

Notes: *the depth of groundwater table for last 3 cases is $2-3 \mathrm{~m}$; **(1) natural groundwater table, (2) self-weight, (3) rainstorm + groundwater table (based on unit weight of saturated soil), (4) external surcharge load $(20 \mathrm{kN} / \mathrm{m})$, (5) earthquake (earthquake intensity VI, or $\mathrm{a}=0.05 \mathrm{~g}$ ).

requirement if the linear failure criterion is used (Table 1). However, when using the hyperbola expression suggested above, the new calculation results show that the required minimum factor of safety for the original landslide may just be satisfied (Table 1). Using linear failure criterion with anisotropy of cohesion $c$ by Equation 2 and $\phi=15.22^{\circ}$ gave very low factors of safety that cannot meet the design minimum requirement. It is therefore important to consider all aspects of mechanical properties of soils including anisotropy 


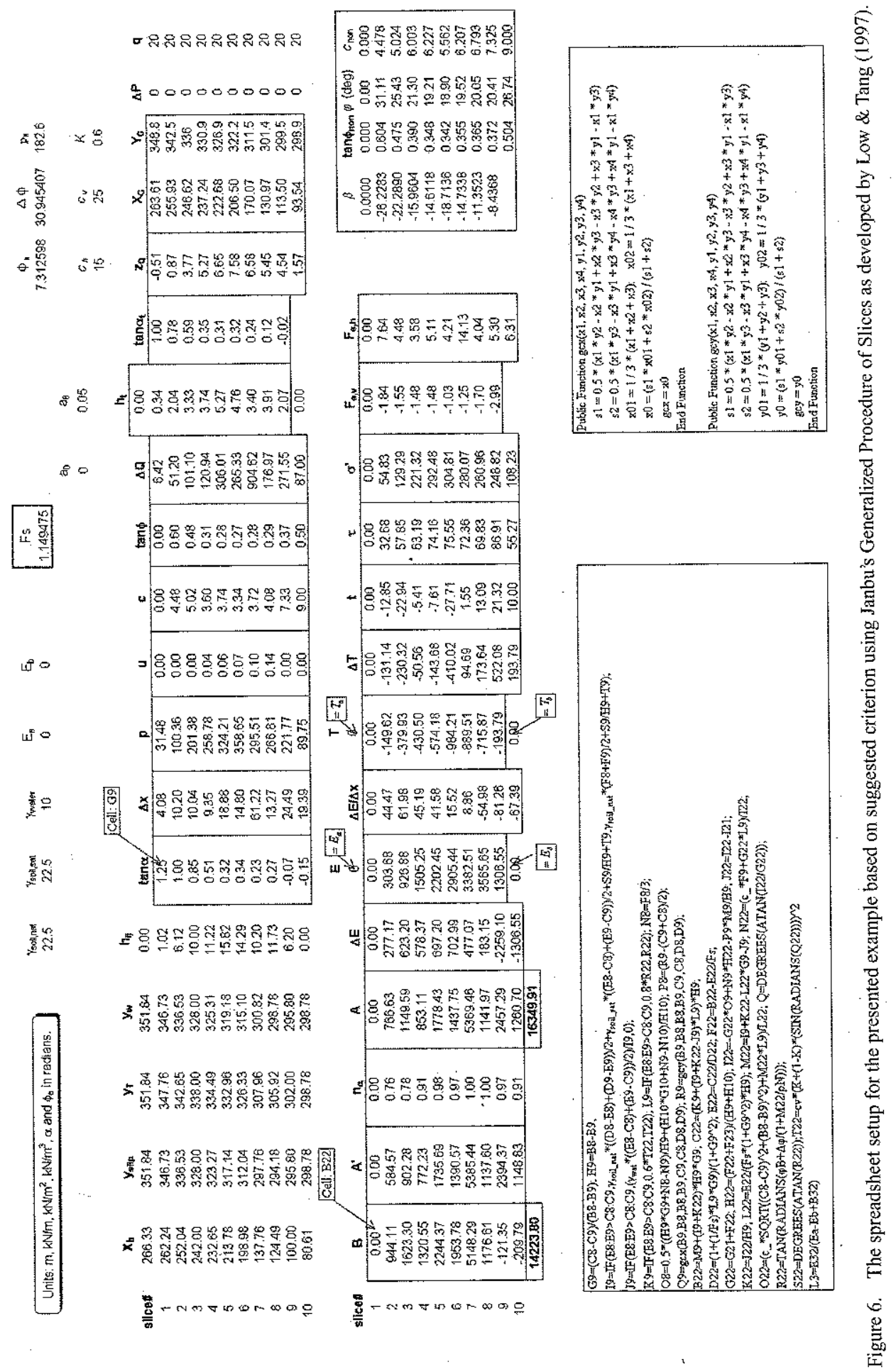


and nonlinearity in order to give a proper assessment of slope stability.

Figure 6 shows a spreadsheet setup for the example problem based on the suggested criterions. The development of this program is influenced by Low \& Tang (1997).

The average relative error $\eta$ is defined as $\left(F_{l}-F\right) / F_{l}$, where $F_{l}$ is the factor of safety obtained using the linear failure criterion while $F$ is based on nonlinear and/or anisotropic criterion. It can be found that $\eta$ due to nonlinearity is $-5.2 \%$ for the present example, which means that considering nonlinearity gives a favorable assessment to the stability of the landslide although this is not always the case in general. The relative error due to anisotropy is $17.9 \%$ for the problem at hand, which means a less unfavorable assessment. The effect of anisotropy of cohesion $c$ on slope stabil ity is always negative. When considering nonlinearity and anisotropy effect, the relative error is reduced to $-12.7 \%$, due to compensating effect.

It can be seen that the different failure criteria will lead to different conclusions about the stability of a landslide or slope and hence greatly influence what stabilization measure that needs to be adopted. However, irrespective of which is to be carried out, good quality large scale in-situ tests for determining the mechanical properties of soil and a comprehensive consideration of all factors affecting the slope is essential for a proper stability assessment of a slope or landslide.

\section{CONCLUSION}

The development of shear strength of soil is influenced by soil dilatancy. Soils exhibiting a nonlinear envelope with a zero cohesion intercept are more common than soils with a cohesion term. In general, a linearized Mohr-Coulomb criterion tends to overestimate slope stability, particularly for a large-scale landslide both at the very low and very high stress range. However, for some landslides for which the range of stress is narrow, underestimation of shear strength may be common. Therefore, a stability analysis of a slope would be more rational if it is carried out based on an evaluation of the nonlinearity and anisotropy characteristics using in-situ tests. The dependency of cohesion $c$ on the direction of external load always decreases the factor of safety, depending on the anisotropic ratio $K$. However, the combined effect of nonlinearity and anisotropy may not necessarily produce adverse results. In most cases, the error produced by the assumption of a linear failure criterion is too significant to be ignored. Further more, the measurement of nonlinearity and anisotropy is not a difficult task using current experimental equipment. Therefore, this is suggested that a failure criterion, which incorporates nonlinearity and anisotropy of soils, should be more widely promoted for slope stability analyses based on the generalized procedure of slice for slope stability.

\section{ACKNOWLEDGEMENT}

The authors would like to acknowledge the sup port of the National Natural Science Foundation of China through grant No. 40372126 and 50179039 ; Key Research Direction Subproject of Knowledge Innovation Project by Chinese Academy of Sciences grounded on grant No. KJCX2-SW-L1; the Special Funds for Major State Basic Research Project by the National Ministry of Science and Technology under grant No. 2002CB412703; and European Commission FP5 Projects OASYS found on No. EVG1-200100061 . The authors are also indebted to Dr. K.S. Li of Victor Li \& Associates Ltd. for reviewing this paper.

\section{REFERENCES}

Al-Karni, A.A. \& Al-Shamrani, M.A. 2000. Study of the effect of soil anisotropy on slope stability using method of slices. Computers and Geotechnics 26:83-103

Bandis, B.C. 1980. Experimental studies of scale effects on the shear strength and deformation of rock joint. Ph.D Thesis, University of Leeds, Dept Earth Sciences

Barton, N. \& Choubey, V. 1977. The shear strength of rock joint in theory and practice. Rock Mechanics 10:1-54

Bishop, A.W. 1966. The strength of soils as engineering material. Geotechnique 16(2):89-130

Casagrande, A. \& Carillo, N. 1944. Shear failure of anisotropic materials. Journal of the Boston Society of Civil Engineers, Contributions to Soil Mechanics 31(4): 1941-1953

Charles, J.A. \& Watts, K.S. 1980. The influence of confining pressure on the shear strength of compacted rockfill. Geotechnique 30(4):353-367

Charles, J.A. \& Soares, M.M. 1984. The stability of slopes in soils with nonlinear failure envelopes. Can. Geotech. J. 21:397-406

Chen, F.H., Snitbhan, N. \& Fang, H.Y. 1975. Stability slopes in anisotropic, nonhomogeneous soils. Can. Geotech. J. $12: 146-152$

Duncan, J.M. \& Seed, H.B. 1966. Anisotropy and stress reorientation in clay. Joumal of the Soil Mechanics and Foundations Division, ASCE 92(SM5):21-50

Janbu, N. 1987. Slope stability computation. In R.C. Hirschfeld \& S.J. Poulos (eds), Embankment-Dam Engineering, Casagrande volume:47-86. Krieger Pub. Co.

Jiang, J-C., Baker, R. \& and Yamagami. 2003. The effect of strength envelope nonlinearity on slope stability computations. Can. Geotech. J. 40:308-325

Lo, K.Y. 1965. Stability of siopes in anisotropic soils. Journal of the Soil Mechanics and Foundations Division, ASCE 91(SM4):85-106

Lo, K.Y. \& Lee, C.F. 1974. An evaluation of the stability of natural slopes in plastic Champlain clays: Nonlinear failure. Can. Geotech. J. 11:165-181 
Low; B.K. \& Tang, W.H. 1997. Probabilistic slope analysis using Janbu's generalized procedure of stices. Computer and Geotechnics 21(2): 21-142

Maksimovic, M. 1979. Limit equilibrium for nonlinear failure envelope and arbitrary slip surface. Third International Conference on Numerical Methods in Geomechanics, Aachen, 1979, 769-777

Maksimovic, M. 1989. Nonlinear failure envelope for soils. Journal of Geotechnical Engineering 115(4):581-586

Maksimovic, M. 1992. New description of the shear strength for rock joints. Rock Mechanics and Rock Engineering 25(4):275-284

Maksimovic, M. 1996. A Family of nonlinear failure envelopes for non-cemented soils and rock discontinuities. The Electronic Journal of Geotechnical Engineering, Premiere. Volume 1:1-62 (See: http://www.ejge.com/1996/Ppr9607/Abs9607.htm)

Saada, A.S. \& Bianchini, G.F. 1975. Strength of one dimensionally consolidated clays. Joumal of the Geotechnical Engineering, ASCE 101(GT11): 1151-1164

Zambrano-Mendoza O., Valko P.P. \& Russell J.E. 2003. Error-in-variables for rock failure envelope. International Journal of Rock Mechanics \& Mining Sciences 40:137-143

Zhang X.J. \& Chen W.F. 1987. Stability analysis of slopes with general nonlinear failure criterion. International Journal for Numerical and Analytical Methods in Geomechanics 11:33-50 